Maximilian von Zedtwitz, and Oliver Gassmann (2002)

\title{
Managing Customer Oriented Research
}

The final version of this manuscript is published in International Journal of Technology Management, 24(2): 165-193.

The final publication is available at www.inderscience.com:

$\mathrm{http}: / / \mathrm{www}$. google.com/url? $\mathrm{sa}=\mathrm{t} \& \mathrm{rct}=\mathrm{j} \& \mathrm{q}=\& \mathrm{esrc}=\mathrm{s} \&$ source=web\&cd=1\&ved=0CCQQ FjAA\&url=http $\% 3 \mathrm{~A} \% 2 \mathrm{~F} \% 2 \mathrm{Fwww}$.inderscience.com $\% 2 \mathrm{Finfo} \% 2 \mathrm{Finarticletoc}$.php $\% 3 \mathrm{Fj}$ code $\% 3$ Dijtm $\% 26 y e a r \% 3 D 2002 \% 26 v o l \% 3 D 24 \% 26 i s s u e \% 3 D 2 \% 2 F 3 \&$ ei=jzksU_GlEI GVhQfA-

oHQBA\&usg=AFQjCNG_C_pUtn7zDhOdGxwa1qbBH4XYMg\&bvm=bv.63316862,b s.1,d.bGE

DOI: 10.1504/IJTM.2002.003050

http://dx.doi.org/10.1504/IJTM.2002.003050

Please note that differences between this manuscript and the final publication may exist. In case of questions, please contact the corresponding author as indicated below. 
Title:

Managing Customer Oriented Research

Authors: (1) Dr. Maximilian von ZEDTwITZ

(2) Dr. Oliver GaSSMANN

Addresses: (1) IMD - International Institute of Management Development

Professor of Technology Management

Chemin de Bellerive 23

P. O. Box 915

$\mathrm{CH}-1001$ Lausanne

Switzerland

max.zedtwitz@imd.ch

(2) Schindler Lifts Ltd.

Head R\&D Technology Management

CH-6030 Ebikon

Switzerland

oliver_gassmann@ch.schindler.com

Erscheint in:

International Journal of Technology Management 2002, forthcoming 
Abstract: $\quad$ Insufficient technology transfer between research and its customers is one of the key weaknesses in industrial R\&D. Since knowledge transfer to development and other corporate partners is the only raison d'être for industrial research, R\&D management should place more emphasis in developing the transfer capacity of its researchers.

Based on analysis of more than two hundred research interviews in 62 companies, we focus on the management interface between research scientists and development teams. We identify five principal dilemmas for managing customer oriented research: the short/long-term dilemma, simultaneity and uncertainty, surrender of project ownership, technocentricity and need fulfillment, specialization and integration. These concepts are illustrated with five examples of R-to-D management at Siemens, ABB, General Electric, EGU, and Rolic.

Although geographical, functional, and socio-behavioral distances call for a stronger consideration of researchdevelopment integration, research must retain a sufficient degree of independence. We propose a transfer oriented model for managing the R-to-D process, from what is possible to what is necessary. Aligning research activities with market requirements may be the only survival strategy for many corporate research centers.

Keywords: $\quad$ Research management, customer orientation, R\&D organization, long-term / short-term dilemma, technology transfer 
Biographical Notes:

(1) Dr. Maximilian von Zedtwitz is a professor of technology management at IMD International Institute for Management Development in Lausanne, Switzerland. He was a postdoctoral visiting fellow at Harvard University between 1998 and 2000 and a research associate at the Institute for Technology Management (University of St. Gallen, Switzerland) between 1995 and 1998. He is a graduate of the Swiss Federal Institute of Technology with a Master's Degree in Computer Science, having a minor in Japanology at the University of Zurich. He worked on MIS development with Siemens in Florida and nucleon simulation research at ATR in Japan before returning to Switzerland where he earned a Ph.D. in Technology Management. His research focuses on international innovation, transnational $\mathrm{R} \& \mathrm{D}$ project management, and technology transfer between research and development. He has published three books and a number of journal articles on international $R \& D$ and innovation management.

(2) Dr. Oliver Gassmann is head of R\&D Technology Management at Schindler Lifts, headquartered in Ebikon, Switzerland. He is responsible for research \& advanced development, competitor analysis and strategic technology management for Schindler worldwide. In addition he is a lecturer for Technology Management at the University of St. Gallen and member of the Swiss Committee for Science and Research (Vorort). Between 1994 and 1996 he was a research associate at the Institute of Technology Management at the University of St. Gallen and lecturer at the business college in Stuttgart. Before he was working in projects at Mercedes (Germany), Norma Products (U.K.), Woco (Ireland), Kolb (Germany) and Festo (Singapore) in the areas of R\&D, production and controlling. He has published three books and over 30 publications in the area of innovation and technology management. 


\section{Managing Customer Oriented Research}

\section{Introduction}

In this paper we argue that stronger customer orientation can be achieved in research without sacrificing long-term research goals. Managing customer oriented research means to proactively design and manage the knowledge and technology transfer from research to all its beneficiaries. These beneficiaries include most prominently development teams in central and divisional $R \& D$ centers, but also researchers in other corporate labs, corporate strategists as well as external partners such as R\&D contractors.

Customer orientation usually implies a focus on the short-term and a narrow scope. However, customer orientation must not neglect the long-term sustainability to perform high-quality research. The very nature of research is to discover unarticulated customer needs and technologies with completely novel applications. Therefore, customer oriented research implies two seemingly contradictory tasks:

1) To fulfill the short-term requirements of customers;

2) To ensure long-term innovative capability.

Research institutes of all disciplines, central research laboratories of large multinational companies as well as independent research laboratories, are confronted with this fundamental conflict [1].

This paper therefore concentrates on the downstream transfer of knowledge and technologies in research. The organizational interface between research and development is significant for the creation, dissemination, and implementation of knowhow and technology throughout the company (see also [18], [19], [25-27], [37], [43]). In many of the companies we analyzed, however, the transfer of technology and knowledge between research and development was dubbed 'ineffective,' 'inappropriate,' or even 'nonexistent.'

Anecdotal feedback from senior R\&D managers highlights the importance of the 'R-toD interface.' Multinational companies have undertaken great efforts to improve the transfer of research results into product development (e.g., Daimler-Benz: [30: 3]). Jim 
McGroddy, former Vice President Research at IBM, even holds that "the key to good $\mathrm{R} \& \mathrm{D}$ management is the linkage between $\mathrm{R}$ and $\mathrm{D}$." The current trend to make use of the most appropriate resources irrespective of their location introduces geographical distance to the barriers of functional and cultural separation which make R\&D even more difficult to manage. Frederick Gorter, Director at Philips Corporate Research Laboratories, maintains that "efficient communication is one of the most important international/multi-site elements of research." And Clifford Detz, manager of longrange and collaborative research programs at Chevron states that technology transfer has been exceedingly difficult because of "the isolation of this (research) function in separate units, often physically separated from a company's other technology activities, and remote geographically and strategically from the needs of the company's businesses" [17: 31].

Managing customer oriented research, i.e. managing idea creation and identification, project selection, and eventual transfer of knowledge and technology, must therefore also take the international dimension of R\&D teams into account. In our examination of the R-to-D interface - across which technology and knowledge transfer takes place-we will focus on problems induced by functional, process-related, and geographical barriers.

\section{Literature Review}

We consider three sets of literature with a broad perspective on technology and knowledge transfer: The first investigating the interface between R\&D and manufacturing and/or marketing ([36], [37]), the second applying an epistemological or knowledge-based perspective ([38], [39]), the third addressing the effects of distance in technology transfer ([11], [32], [33]). Neither focuses on the management interface of R-to-D.

Although there is some literature on the transfer of know-how between research and development ([18], [19], [21], [40-42]), most of it is on the transfer between academic research and industrial $R \& D$. In general, contributions regarding the integrating of industrial research and development activities neglect the international dimension ([2527]). Contributions from R\&D practitioners are strongly based on cases from their 
respective research organization, providing interesting lessons for managing technology transfer and improving customer orientation in industrial research ([31], [34], [35]). Cohen, Keller, and Streeter of IBM [18] discuss primary and secondary factors which are important for successful transfer from research to development. 18 years later, Gomory [19] underlines the importance of joint programs for technology transfer at the same company. Outlining some principal impediments to technology transfer, Detz [17] argues for corporate long-term research programs which are explicitly aligned with corporate business drivers and their underlying strategies. He suggests a footprint metric and shared ownership for transferring from long-term to business unit R\&D.

R\&D-internal technology transfer has been examined from various process-related perspectives. Nitta and Belady [20] outline three phases in technology transfer at a research laboratory of Mitsubishi, laying emphasis on project initiation, collaboration with development, and establishing common practice once the transfer is complete. They note that technology transfer must start concurrently with the research project. Eidt and Cohen [21] describe the redesign of research at Exxon towards embracing input to research from all business levels, a business-driven approach that articulates targeted science advances in clear technical terms, and a seamless link to ongoing applied development research. This system is based on a hybrid arrangement of both centralized and decentralized features. Cohen, Kamiensji, and Espino, notably from the same organization, describe the extension of the Stage-Gate paradigm into industrial basic research [22]. They underline the knowledge-building function of early R\&D stages, and the importance of gatekeepers as nurturers and decision/makers for new technology. In this way, basic research is more integrated with applied and exploratory R\&D. Chester [23] makes a similar argument for more business unit direction of central research projects as well as result-based compensation for research employees.

Contributions from academics and consultants have opted for more generalization. Based on research in eleven American and Japanese companies, Khurana and Rosenthal [24] identify the "fuzzy front end" as one of the greatest weaknesses in product innovation. Proposing seven critical activities, they distinguish between foundation and project-specific elements. They argue that these elements are often only independently considered and therefore they leave plenty of room for optimization. With substantial insight from their consulting practice, Eldred and McGrath ([25], [26]) investigated the 
early technology development process and suggest to consider technological performance as well as project duration for successful technology development. They propose the concept of a technology feasibility point, around which a number of organizational measures form the basis of TRAC (Technology Realization and Commercialization), a structured evaluation process for technology development.

Investigating the fundamentals of integration of research and development, Iansiti [27] looks at the role of technical decision making in complex, novel, and rapidly changing $R \& D$ environments. He proposes the concept of technology integration which is aimed at creating a match between technological options and application context, i.e. at linking fundamental knowledge domains to each other and to their context of application. The elements of an effective process for technology integration are mechanisms for knowledge generation, knowledge retention, and knowledge application. His work is based on data collected in the 1990s and comprises microelectronics and software manufacturers.

It is interesting to note that much of the research leading to the present state of knowledge is strongly case-study based. There are differences in the number of cases considered as well as in analytical methodology. Nevertheless, there is a commonly shared belief that customer oriented research calls for a more deliberate management of technology and knowledge transfer from research to development.

Calling for the undisputed alignment of research with customer expectations, however, would be the wrong solution. The customer of technology, states Frosch [16], is frequently wrong about the requirements. The customer's problem formulation is either too shallow or short-term, or it is a narrow definition of what the customer thinks is the problem. Eventually, research will have to solve practical problems for customers unless it is funded entirely customer-neutral through government support or from a corporate budget. However, studies show that research centers of technology-intensive multinationals are increasingly financed by those business units for which they conduct projects as negotiated contract research (Fig. 1). Business unit financing does secure 'money-sponsor orientation' but not customer orientation, although it is a step in the right direction. Frequently, R\&D scientists are indifferent about who actually pays for 
their research projects. Real customer orientation therefore calls for more effective management methods.

// Fig. 1 about here //

\section{Research Methodology}

The conceptual starting point of our research is a four-structure model of R\&D organization, which describes the most relevant issues in $R \& D$ from a perspective of organizational change and communication ([2], [45-47]). According to this model, we analyze regional/legal, hierarchical/functional, process/project, and informal links/network issues. The research was carried out between 1994 and 1998 with support from the University of St. Gallen and the Institute for Technology Management as part of a research program studying international R\&D processes (Fig. 2). The entire program consisted of two phases: Phase 1 focused on the management of transnational R\&D processes, Phase 2 focused on the explanation of the observed trends and the internal differentiation of international R\&D organization (see also [2], [3], [47], [48]).

// Fig. 2 about here //

In accordance with Yin [28] we pursued a case study-based approach to our research. The data was collected by means of personal research interviews. An interview guideline was used to maintain coherence of data collection throughout the research phase. A total of 290 interviews on international R\&D management were conducted during the entire research program. $R \& D$ directors, $R \& D$ laboratory managers, and $R \& D$ project managers were interviewed. Interview data was complemented by desk research, namely the analysis of company publications (annual reports, internet web pages, internal journals), internal memos and presentations as well as project reports. Moreover, in follow-up sessions with interview partners, the interpretations were confirmed for each company (triangulation of data collection methods: [49: 24] and [28: 45]).

We have chosen five cases (Siemens, General Electric, ABB, EGU, and Rolic) from our investigation sample to highlight central observations in customer oriented research management in industry: Ensuring long-term innovation, empowerment, time-to-market reduction, need fulfillment, and customer integration. 


\section{Ensuring Long-term Innovation: Positioning Central Research at Siemens}

Roadmapping is a powerful tool to time the introduction of new technologies and products, integrating business and technology strategy. These functions are critical in ensuring the long-term innovative capability of research-based companies. Large companies in particular-like Philips and Siemens-employ this technique. Siemens also coupled roadmapping with multiple generation product planning to create more customer orientation in research [8].

\section{Roadmapping and Technology Planning at Siemens}

With more than DM134 billion in sales in 1999, Siemens is one of the world's largest providers of electrical and electronic products. 300 business areas are clustered in eight large core businesses (energy, industry, communication, transport, health care, components, household, and lighting). 46,700 employees are engaged in R\&D. Spending DM10.240 billion on R\&D in 1999, Siemens is one of the most technologyintensive companies in the world.

Diversification creates customer proximity in business units but removes crossdivisional research from immediate market requirements. With R\&D in over 25 countries, particularly the US and Europe, Siemens is strong in local product and services adaptation. More than a fourth of Siemens' research is conducted outside Germany. Since customer orientation often implies a strong local foundation, the company strives to be a 'good citizen', creating complete value chains ( $R \& D$, production, distribution, and marketing) in each country it operates. R\&D has also been established where capable engineers and scientists were available. For example, software can be produced remotely and easily shipped anywhere. Siemens hence operates large software development centers in Spain and India where personnel expenses are lower than in Germany. Siemens also collaborates with leading research institutions to reduce in-house development costs, amounting to more than 1,000 cooperative research projects.

Siemens Corporate Research is the core of the company's R\&D research and development technology activities, with 1,100 scientists and engineers in MunichPerlach and Erlangen (in Germany), and Princeton, New Jersey. Although its explicit 
responsibility is to ensure long-term innovation by generating potential breakthrough projects, it has to deal with the full range of innovation including incremental innovation projects. Corporate Research has thus to develop and maintain technological synergy. Each of the Corporate Research departments covers one cluster of strategic importance to the company's core technologies. R\&D operations are concentrated in projects with clear objectives, defined time horizons and cost margins (see Fig. 3).

// Fig. 3 about here //

Long-term innovation is based on an $\mathrm{R} \& \mathrm{D}$ program which is negotiated in a complex selection and communication process between Corporate Research and the business units. The most important instrument in the $R \& D$ program is technology planning based on roadmaps: Technology requirements derived from future product generations are compared with anticipated technology evolution with a planning horizon of about five years longer than in the business units. Technology planning facilitates the transfer of $\mathrm{R} \& \mathrm{D}$ results from long-term projects into short- and medium-term close-to-the-market R\&D programs.

Much of Siemens' long-term R\&D is carried out in predefined innovation fields, providing a focus for monitoring future $R \& D$ areas and potential innovation drivers as well as ground-breaking basic research. In contrast to technology planning, innovation fields are conceived in a top-down holistic approach. They are subject to a long-term horizon and aim at anticipating technological or market discontinuities, as well as generating new business opportunities. Scientists involved in innovation fields research deal with a time horizon of up to 20 years, thus making their work sometimes quite detached from direct market needs.

The 'Core Technology Roadmaps' at Corporate Research are complemented by 'Multiple Generation Product Planning' (MGPP) in Siemens business operations. The two-stage MGPP combines product and technology planning at a business level. In the first stage, business area roadmaps according to product groups or systems are drafted. Fig. 4 shows an example of the Automotive Systems Group. In the second stage, a three-step process is implemented to determine key systems and processes, as well as key components, core processes and core technologies.

// Fig. 4 about here // 
Apart from the systematic definition of technology needs for the business areas, this tool is helpful in make-or-buy decisions. Useful synergies are highlighted along the referential links. Technologies thus recognized as necessary are compared to the actual stock of technologies available. The evolutionary development of these technologies is depicted in technology roadmaps.

Each core technology roadmap consists of 'roads' defined in the language of the customer, i. e. the language of the business operations. Dark gray shaded areas indicate core technology topics in which Corporate Research is able to secure competitive advantages for business operations. Technologies in which Corporate Research is not (yet) present are marked light gray. A technology roadmap leads to an all-encompassing technology vision. This vision is also communicated as a long-term plan to nonindustrial research institutes.

It is the aim of this broadly-based technology planning to visualize central $R \& D$ activities in core technologies as well as in the design of large projects. Corporate Research and decentralized development units in business areas are forced to develop a shared point of view on supply and demand, which should eventually result in clearly defined project agreements. Due to the dynamics in technology and the business environment, technology planning is a revolving process that is to be applied and updated at least once a year.

\section{Discussion}

Product-technology roadmaps require a good understanding of markets and applications since it is necessary to define products in terms of customer requirements. Based on the roadmap, technical functions of products and the required technologies to realize these functions are determined. These activities help to improve the front-end of the product creation process $([6,7])$.

The main benefits of roadmapping are [6: 50-51]:

- Improvement of time-to-market and time-to-money;

- Improvement of cross-functional communication;

- Interlinking of long-range product and technology planning and vision building; 
- Establishment of a shared product-technology strategy;

- Support of working in processes.

Long-range research planning and technology monitoring are particularly useful for large companies with complex technology creation processes. For instance, they have helped Pioneer Electronics to attune its research to future markets and keep critical technology in-house [9]. By anticipating future demands based on sound technology forecasting, Pioneer was well positioned to move pre-competitive fundamental research into focused $\mathrm{R} \& \mathrm{D}$ projects, eventually bringing commercial products into the market quickly.

Meanwhile, most research institutes of large technology intensive companies - e. g. ABB, IBM, United Technologies, Bayer, Hoffmann-La Roche - move from predominantly scientific research towards market-oriented research understood as service for customers, partly in consequence of a decrease in the level of government funding and a reluctance of business units to support long-term and market-distant research.

Although technology planning and roadmapping are a excellent management tools to align central research and decentralized development [6: 55], companies with a strong function-orientation often have difficulties to initiate roadmapping. Their roadmaps are independently drafted for each function without recognizing the synergy potential between the entire company. Management must then ensure that multifunctional cooperation takes place. However, management support may be difficult to obtain if roadmapping is regarded as 'just another' tool for strategy definition and communication improvement. Starting the roadmapping process bottom-up helps to demonstrate its benefits.

Roadmapping is no quick solution to existing R\&D problems: The time and effort required are often underestimated. Since roadmapping is a revolving exercise, interrupting this process means that much effort and time is needed to regain the momentum. If roadmapping becomes common practice, however, the integration between technology and customer strategy, communication and cross-functionality is greatly supported. 


\section{Integrating Business Units: Sharing Ownership at General Electric}

R\&D units will have to solve practical problems for customers unless they are funded by government money or a corporate budget. Research in technology-intensive multinationals is increasingly financed by business units through contract research projects (see [23], Fig. 1).

However, business unit financing alone does not ensure customer orientation. Many scientists in R\&D labs are either indifferent or unaware of where the funds for their research projects come from - as long as the money come in. Customer orientation therefore calls for more effective management methods. General Electric has therefore coupled a funding reform with a reorganization of how R\&D is operated.

\section{Coupling Business Unit Funding with Cross-Functional Teams at General Electric}

General Electric (GE) is famous for being No. 1 or No. 2 in each market they operate. Recognizing that this ranking depends very much on how narrow the markets were defined, GE redefined many of its markets such that their market share dropped below the $10 \%$ or even $1 \%$ level. This misperception shifted thinking at GE from established businesses to new opportunities [4].

In the $1980 \mathrm{~s}$, GE reacted to the challenges of speed, costs, and quality by making fundamental changes in R\&D [4]. These changes included:

- The funding system;

- Creating the boundaryless company.

In the previous funding system, two thirds of the corporate $R \& D$ budget were 'assessed funds' granted by the CEO's office. This was changed to a system in which $50 \%$ of the funds had to come from contracts with GE business units, $25 \%$ from external contracts, and only $25 \%$ from assessed funds. Business units are now free to acquire research services from anywhere. They are allowed to conduct research themselves, and collaborate with universities, national labs, or even competitors. The only constraint is that they are not allowed to cut their funding for corporate R\&D by more than $20 \%$ per year. 
The GE Corporate R\&D Center serves all of the 12 GE businesses, employing 1,575 scientists from various engineering and science disciplines. The overall R\&D expenditure of US\$1.8 billion is distributed among the R\&D Center and 25 laboratories with a total staff of 8,000 scientists and engineers (see Fig. 5).

// Fig. 5 about here //

The new market oriented funding mechanism makes sure that GE's Corporate R\&D Center works on projects which are vital to its business units. The actual funds allocation is decided in close cooperation with key customers in the business units. Some one hundred key objectives are identified at the beginning of each year, and their progress is tracked and reviewed regularly.

At the end of each year, the customers decide how well the R\&D Center has achieved the objectives. This system achieves a higher customer orientation than elaborate project portfolios which are 'sold' to the business units. The R\&D Center is measured not in technological or scientific achievements but based on how well it served the businesses. This is done mainly by 'voting dollars', i. e. in terms of the amount the business units are willing to pay for research the next year. At the same time, the $25 \%$ of funding from corporate headquarters enables the R\&D Center to select and work on high-risk, exploratory, or unpopular research projects for which business units were unwilling to pay.

The other fundamental measure to restore customer-orientation was the removal of boundaries between GE units. In R\&D this meant intensified cooperation between the R\&D Center and the R\&D departments in the business units. Such cooperation fosters the creation of shared values and a uniform language for the entire company. Researchers team up with engineers from development, manufacturing, marketing and service experts from the business units. Unlike sequential project execution, when intermediate project results were handed over to business unit teams, members of cooperation teams work together from the beginning of a project to the end, often in a location close to the eventual customer. The term 'one coffee pot' teams has been coined to describe this approach, because the team members are gathered at the same table, around the same coffee pot, throughout the project. Since team members are involved from the early project creation stages to the roll-out, they all own the project regardless 
whether they were mostly involved during the technology creation phase or later during the specification or adaptation phases.

Working in cross-functional teams often means that researchers work on the factory floor. As part of the Center's technical support, researchers are directly involved in working with external customers, going into the field to utility plants, as well as becoming part of business teams.

\section{Discussion}

The role of corporate $\mathrm{R} \& \mathrm{D}$ during much of this century was to improve the performance of products and occasionally creating new ones. In the past ten years, the rules have changed: Faster accomplishment, lower costs, and higher quality have to be achieved without sacrificing performance and innovation. The globalization of markets and technology introduced new customers, new opportunities, and new competitors. Higher speed from laboratory to markets was needed, at lower costs, and with products of higher quality.

Those companies with established rules of how to run R\&D were especially challenged. GE was focused on research for technology's sake, irrespective whether that technology would contribute to businesses or not. This mind-set changed. Today, every GE researcher works in a project with an identified impact on future products and services, or in a high-risk program with the potential to create an entirely new business. This was achieved by adapting the funding system as well as requiring every researcher to work in cross-functional teams. Ownership and responsibility of research is thus shared by $R \& D$ scientists and engineers in business units. Coupled with a balanced funding scheme, shared ownership reduces the barriers transferring research to the business units after completion of the $R \& D$ project while simultaneously increasing the fit of research with the needs of the market.

\section{Reducing Time-to-Market: Geographic Centralization of Interdisciplinary Research Teams at ABB}

Physical distance is detrimental to communication [11]. Local market presence of $R \& D$, however, is often associated with improved customer-orientation. Unfortunately, coordination, knowledge transfer and cross-functional cooperation between corporate 
research centers and internationally dispersed development units is extremely complicated and difficult to realize. Hence, many companies continue to conduct core technology research in their home country [12].

\section{'Heavyweight' Project Management at ABB}

In the early 1990s, ABB realized that the higher-end turbine market was slipping way from them. With little time available and the competitive advantage disappearing fast, ABB set up a large-scale $R \& D$ project to develop a new generation of gas turbines (the GT24/26 turbines). New management methods were employed, among them some aligning breakthrough $\mathrm{R} \& \mathrm{D}$ with customer expectations and simultaneous engineering including research, development, and manufacturing $([3,10])$.

GT24/26 was the first simultaneous engineering project of this kind at ABB. As the pressure to reduce development time was enormous, ABB pushed for product development before the necessary material research was completed. In order to simultaneously develop end-product components while fundamental research was still under way, research and development was collocated in just one building in Gebensdorf, Switzerland.

// Fig. 6 about here //

Due to high R\&D costs and urgent time pressures, ABB employed the concept of innovation marketing: the close interaction of $\mathrm{R} \& \mathrm{D}$, marketing, and innovative product users. Innovation marketing aligns internal and external technological constraints by coordination among the main innovation participants, improving technology transfer, cross-functional communication, and market introduction times. The principal management approach combines heavy-weight project management, design-formanufacturability, benchmarking, and simultaneous engineering.

ABB's top management fully supported the project, yielding considerably authority and decision power to the GT24/26 development project manager. Cross-functional teams, lead users, researchers, and development engineers collaborated during the entire project. The GT24/26 generation was a technological breakthrough and moved ABB from a late follower into a technical leader in the field of high-end turbines within a short time period. Compared to previous projects, time-to-market could be reduced by $60 \%$ and the number of modules by nearly $50 \%$. 


\section{Discussion}

Centralizing research teams can be a difficult decision because of the superior costs involved. But when critical aims are at stake, like in the ABB GT24/26 case, the advantages of centralization clearly compensated for possible disadvantages. Due to the massive utilization of modern information technologies in $R \& D$ and the increasing importance of transnational R\&D projects, we expect the necessity of collocating decentralized development teams with central research groups to become less pronounced. Especially when information can easily converted to code and team members know each other already from previous projects, cost-intensive centralization can be reduced to kick-off and review meetings. Conducting R\&D projects at separate locations requires frequent travel and the use of modern communication technologies. But modern information and communication technologies cannot replace face-to-face contacts for extended periods of time. While collocating R\&D teams is very costly and sometimes next to impossible, the $\mathrm{ABB}$ example suggests to also consider temporary group assignments to central projects in order to bring key researchers, scientists and engineers together. This is especially important in projects where time-to-market is important and much of the R\&D work has a systemic, breakthrough character. Here, the interface between research and internal customers is a matter of tacit knowledge exchange and transfer of innovative technologies.

The integration o lead customers served two purposes. First, the product was developed under critical review from eventual turbine users. This helped the elimination of unwanted product functions and the introduction of new additional features. Second, ABB could point to the lead user as a reference customer-and this is particularly important in a business where already the purchase of a single product is a large-scale and long-term investment. Last but not least, the early involvement in the R\&D process was also beneficial to the lead user, as he obtained a well-tuned high-power gas turbine for a fraction of the market price but well ahead of his competitors.

\section{Towards Need Fulfillment: Matrix Organization in Research at EGU}

There are basically two polar alternatives for organizing $R \& D$ in manufacturing business: function-centered and business-centered. Functional R\&D organization can 
generate and maintain long-range research, building on scale effects and the establishment of scientific professionalism. Business-centered R\&D geared towards customer needs, but the effort is often short-range and low-risk. Superimposing marketoriented, cross-functional teams can make a significant improvement to the functioncentered structure.

\section{Changing the Mind-Set at EGU}

For EGU, an R\&D company in the energy production engineering sector in former Czechoslovakia, the principal challenge after the fall of the planned economy was to move from technology-centered predetermined demand to a market-driven customeroriented mind-set [13]. Due to its functional hierarchy and concentration of defined technologies, however, there was little freedom for creating new technologies. The old organization (Fig. 7) was changed because it faced the following three problems:

1. Differences between corporate and market structure prevented an effective transformation of in-house competencies into marketable services and products. EGU's activities were focused on the wrong market segments.

2. Synergies between technology competencies and potential success factors were not exploited and prevented a clear distinction from EGU's competitors.

3. As the development of services related to EGU's core businesses was not supported, potentially profitable market-segments were not discovered and expanding EGU's business fields were restricted.

\section{// Fig. 7 about here //}

Merely establishing a marketing department would not solve the discrepancies that had evolved between company organization and its competitive environment. With the help of a German consulting company EGU aimed at developing a structure which combine technology and market-driven innovation: a matrix organization (Fig. 8).

The eventually implemented organization concentrates internal resources in "technology centers" (TCs) and directs target-group specific services into "strategic business unit centers" (SBUCs). In order to facilitate the integration of radical innovations into everyday business operations, temporary cross-functional project teams were set up. Combining the matrix with an interlacing project structure secured efficient resource 
pooling and resulted in a multi-dimensional matrix organization. A well-organized multi-project management now allows efficient know-how transfer and customer orientation.

// Fig. 8 about here //

SBUCs are fairly independent from EGU, being fully responsible for their own profit and executing self-developed strategies. In each SBUC a contact office directly addresses and coordinates customer service; independent distribution departments and order management are in place. The acquisition of new projects is also left to SBUCs, and the coordination of corporate resources for execution of a complex project reside within these units. The projects are then led by members of the SBUC to ensure customer focus.

In consultation with project leaders from SBUCs, TCs provide manpower and other resources. TCs are responsible for the operational execution of projects. By focusing on leadership in a particular technology and the improvement of methods and systems employed, they maintain a high profile within the technical-scientific community and the respect and trust from customers and competitors. A TC will only be established if a market demand for the respective technology can be identified. The concentration of competencies in a TC is evaluated on the basis of minimum customer requirements and comparable competitor performance potentials. This also determines the investment share of participating business areas.

Non-competitive TCs are held to refocus their technological resources. If this is not possible, the individual technologies will be given up or removed from that TC in order to restore overall competitiveness. The TC evaluation follows a formal three-step procedure:

1. Identification of quality and quantity of the available resources under consideration of machinery equipment on the one hand and know-how of the employees on the other.

2. Evaluation of the resources by measuring them in terms of the minimal technology requirements which potential customers in the respective business areas might have. 
3. Comparison of own performance potentials with those of the main competitors.

The technologies employed for service and product generation play a minor role in SBUC formation, since a SBUC is defined with the customer and not the technology in mind. The main business issues are the customers, the services they demand in their individual market segment, and customer problems that may not yet be solved by the services offered by the SBUC. Last but not least, the concentration of individual activities in SBUCs improves transparency for customers who want to identify the appropriate contact quickly for their specific problems and expect optimal service throughout the entire project duration.

\section{Discussion}

Organizations striving for business as well as technological excellence will need employees in both walks of life. Especially in customer-oriented business functions, extroverted people with salesman qualities are required. Scientists and engineers are primarily hired for their technical expertise and usually known for their analytical rather than marketing skills. Ideally, a combination of technically trained and businessoriented people will identify customer problems quickly and serve as interpreters between customers and internal technology centers.

If a company fails to fill the business positions with qualified managers and customer oriented engineers, the long-term entrepreneurial progress is at risk. The step from technology to customer orientation takes time to effectuate in the minds of many employees. Appropriate training and education must support changes in management and organization. Even the best strategic reorganization is of little value if the employees cannot implement the new ideas and guiding rules in their daily work.

\section{Customer Integration: Research Spin-off Rolic}

Spin-off companies are commonly regarded as small ventures, freed from the organizational constraints of their parent organization, commercializing new technology or know-how [14]. The removal of unnecessary overhead and hierarchy improves efficiency, while the separation from the parent's main-line strategy allows the spin-off to assume its own identity, allowing operational and strategic freedom. The new company is thus in a better position to more effectively apply its technological expertise 
to specific customer needs. Rolic, a research-based company engaged in liquid crystal (LC) substance development and LC engineering, was separated from Hoffmann-La Roche (Roche) because its electro-chemical business focus diverged too far from the pharmaceutical business of its parent organization.

\section{Customer orientation in Small Research Companies: Networking at Rolic}

Schadt and Helfrich at Roche and engineers at Brown Boveri \& Company (BBC, merged later with ASEA to form $\mathrm{ABB}$ ) discovered the fundamental liquid crystal technologies in the early 1970s [15]. In an attempt to diversify into new businesses, both companies tried to develop the technology further. However, due to an unsuccessful cooperation between the two companies and negative feedback from potential markets, they experienced great difficulties in commercialization. Despite a strong position as a LC supplier and a firm hold of key patents, Roche's profits from the LC business remained negligible. Moreover, research in liquid crystals was never fully accepted at Roche because it was too removed to the pharmaceutical core activities at Roche.

At the beginning of the 1990s, after several attempts to find an appropriate place and organization for its LC research group (see Fig. 9), Roche decided it to terminate R\&D in LC substances but agreed to support the highly innovative team with venture capital. The LC group was organizationally separated from Roche research although it remained physically in the research laboratories in Basel, Switzerland. Rolic Ltd. was established as a research company of approximately 30 scientists with the designated goal to carry on LC-related research under the leadership of the original inventor, Martin Schadt. With this spin-off, Rolic gained strategic and operational flexibility unknown to the LC research group before.

As a newly established company, Rolic actively sought to include customers in its research program. This called for the following agenda:

- Mission-guided research: Under Schadt's new role as business champion, the team organized itself without functional confinements but with dedication to the research objective and the development customers. 
- Greater transparency: Due to strategic and operational freedom and flat hierarchies, decision processes were less complex and more focused. Responsibilities and competencies were clear. Operational efficiency was increased.

- World-wide R\&D networking: Scientific credibility and personal acquaintance with the leading LCD developers opened doors for Rolic's researchers. Personal presence through the exchange of R\&D personnel maintains trust and know-how transfer.

Technological know-how is vital for Rolic in obtaining a strong position in emergent technologies and reducing time-to-market. It is Rolic's explicit strategic intent to develop their research products in close contractual collaboration with a few selected high-tech device manufacturers from the early prototype stage to the innovative, manufacturable product. For this reason, intensive R\&D personnel exchange with lead customers is an important instrument to ensure efficient joint development. Rolic also provides consulting and technology transfer until the industrial realization of the LCD device is secured.

In 1998, Rolic entered a licensing joint venture with BTG, a world leader in the management and commercialization of Intellectual Property Rights, in order to support its own patenting and licensing efforts. This agreement is dedicated to the worldwide management of Rolic's patent portfolio, its commercialization, and certain new LC applications in document security industries. By licensing out its LC patents, Rolic is able to supply the proper and appropriate liquid crystals already at the beginning of the production process of new devices. Based on its device and chemical patents, Rolic earns a considerable portion of its total income in royalties. R\&D is focused on new electro-optical devices, device-specific organic substances, and the application engineering in cooperation with electronics and chemical companies. Rolic itself does not engage in mass production of these devices and device-specific substance but helps its licensees to acquire the necessary manufacturing technologies.

\section{Discussion}

The spin-off into an independent research company was an important step towards customer oriented research. The establishment of Rolic as an independent missionguided research company was a logical consequence of the growing divergence of the LC activity with drug-related R\&D at Roche. Schadt's personal dedication and 
interdisciplinary vision initially bridged the traditional gap between the chemistry and physics laboratories at Roche, but in the long run, Roche was not the right home for liquid crystal research. It took long for a determined business champion to identify the full market potential of the LC group and the make critical decision to go separate ways.

The Rolic example also illustrates the extremely interlaced network between research, production and customers in the chemical industry. Adequate management of information and mutual trust are indispensable in $R \& D$ cooperation or strategic alliances. The technological competence and the innovation potential of each alliance partner in his respective special field is also of central importance. For instance, Rolic has granted Ciba Specialty Chemicals exclusive responsibility (except Japan) of process development, production, marketing, technical service, sales and distribution of Rolic's breakthrough linearly photopolymerizable polymer (LPP) and liquid crystal polymer (LCP) chemical materials. Under this license, Ciba collaborates with Rolic on the commercialization and manufacture of this class of functional chemicals.

By concentrating on the value chain in downstream industries, Rolic was able to achieve customer orientation for long-term research and innovation. A research-driven invention without an envisaged target market or even a vague conception of product design had thus found a new opportunity after long years of uncertainty and battles for in-house acceptance in a new organizational and strategic framework of an independent research company.

\section{Implications for Customer Oriented Research Management}

In technology-intensive firms, the two most prominent factors determining the business environment are technology and customers. Customer oriented research management is understood as the consequent alignment of research activities with the needs of internal and external customers. While basic research laboratories understand themselves as scientific institutions largely removed from direct market tribulations, engineering companies have realized that they are service providers operating in an increasingly open and aggressive market. Due to the relative decrease of funds for basic research and the growing understanding of downstream corporate operations as internal customers 
(such as development and manufacturing), research must be designed as a customer oriented and market oriented service.

\section{Cross-Case Analysis of Customer-Orientation}

The five cases presented here were selected from our investigation sample based on how well the illustrate principal dilemmas in customer oriented research management. The companies differ in many aspects: industry, strategy, overall organization, and their approach to R\&D (Table 1).

// Table 1 about here //

Customer oriented research does not imply that all R\&D is carried out by business units. Research must remain a distinct functional force in its own right. Customer ideas and customer requests are adopted through strategy development processes, structural crosslinkages, or special integration tools. But customer orientation requires more than the utilization of tools such as quality function deployment and failure mode and effect analysis. The mind-set of a company must shift from a technology focus towards external behavioral orientation. This mind-set is reflected in how the research-tocustomer interface is designed. In our case-study research we have identified some important factors that determine the collaboration over this interface (Table 2).

// Table 2 about here //

One of the major challenges is that the time required for research to get to results is much longer than the time available to solve current problems: Industrial research is not on the same time scale with development in business operations. This time lag can amount to 10 or 15 years. However, research funding is based on its contributions to present profits: Research must therefore sell to future customers just as well it must satisfy current demands.

The cases illustrated some very specific mechanisms to link research to customers. The management of these linkages takes place on four distinct levels. At the functional level, innovation plans and research areas are jointly defined and approved by both research and customers. These plans must take into account the technological uncertainties inherent to research and advanced development. It is important that any long-term research effort can rely on the continued support from top management and its 
customers. Technological uncertainties should not be artificially complicated with financial insecurities.

A matrix organization with technology centers and strategic business unit centers focuses internal resources on valuable services for relevant customer needs. At the project level, cross-disciplinary teams representing scientific expertise and application know-how ensure cross-functional learning and the quality of research. Cross-functional teams help transforming function-centered $R \& D$ operations towards more customer orientation. The appropriate time to switch from a research-driven effort to a customerled endeavor depends on the maturity of technology and the competence of its customers.

An often neglected arena for managing customer orientation is the level of informal networks and linkages. Regular job rotation between research and business units reduce the ivory tower syndrome. Intranets and shared utilization of databases and communication platforms helps to maintain links once established. Modern information technologies can reduce frequent travel, but face-to-face contacts remain vital for initiating and harmonizing personal and professional relations. Knowledge best travels with heads, and is best communicated face-to-face. This calls for temporary rather than permanent assignments.

In order to intensify cooperation between research centers and internally decentralized development units, collocation of interdisciplinary teams may be necessary. However, for reasons discussed above, collocation must always be complemented by increased information feedback to the contributing partners. At the geographical level, physical dispersion is often seen as an impediment to customer orientation. As part of an integrated R\&D network, individual R\&D units must learn from the knowledge creation elsewhere in the network. Collocation of $R \& D$ teams and critical skills is often more costly than assumed. If collocation and seamlessness of R\&D processes are not an option, then functional and geographical impediments must be accepted and overcome. This requires better skills to transfer knowledge from research to development. R\&D management must therefore place more emphasis on the following three issues:

- Dealing with inherent dilemmas of customer oriented research;

- Making customer orientation a responsibility of every scientists; 
- Developing the transferring capacity of its researchers.

\section{Dealing with Principal Dilemmas in Research Management}

As a consequence of external and internal pressures, $R \& D$ management had to adopt the concept of customer orientation. Customer orientation is in many ways incompatible with the traditional understanding of long-term research. While some of efforts towards customer orientation had hence only cosmetic character, a number of companies now stand out as leading examples for modern research management. These companies, we believe, have successfully come to terms with some inherent dilemmas in managing research under the new paradigm. Five of these dilemmas were illustrated by the case studies; they are summarized below:

1. Long-term vs. short-term: $\mathrm{R} \& \mathrm{D}$ is aimed at reducing technological uncertainty and improving market fitness. The framework in which this work takes place must be adapted in accordance with technological maturity and business proximity. Research management is geared towards pushing the technological frontier forward, but should also support the future application of its technology. This is demonstrated by technology planning and road mapping at Siemens.

2. Leadership vs. ownership: As a leader in an established market, the danger is high to become a victim of one's own success recipe. Established routines must quickly make room for new opportunities. Development teams in business units are in closer touch with the market and should therefore assume more control over research projects when they concretize. Cross-functional project teams should be established early, allowing the customer to co-own the technology developed in cooperation with research.

3. Sequential vs. simultaneous: Clear separation of work tasks and secured technical parameters reduce R\&D complexity and improve manageability. However, evershorter development cycle times require in certain cases even a simultaneous development of technology and product at the same time. ABB's centralized venture team organization integrates research, development, and lead-users to achieve highimpact goals in short times. 
4. Technocentricity vs. need fulfillment: Corporate research should act as a real partner instead of a budget-maximizing antagonist. "Technology-push" thinking is a frequent and major obstacle to customer-orientation. Our EGU example illustrated the first steps from a traditional, socialist research institute into a modern, marketoriented matrix organization and multi-project management. In order to overcome technocentricity some companies like BMW or Schindler integrate markets and technology research; Sony's research manager Europe is also responsible for new business development. Business orientation and understanding the customers' problem are the key for real need fullfillment.

5. Specialization vs. integration: While internal expertise is important to provide the technological foundation, leveraging external skills and opportunities make an equal contribution to the innovation. The compartmentalization of research departments can be addressed by cross-functional projects. But business responsibilities as faced by a complete spin-off of a research unit more naturally promotes the integration of technology and marketing thinking. The fate of liquid crystals at Hoffmann-La Roche and Rolic is a case for direct customer interaction and personal networks.

These dilemmas should not be considered as trends. Corporate research must not fall from one extreme to the other. We must learn to balance these dilemmas and guide the innovation effort through the often diverging requirements from research and customers.

\section{Customer Orientation in Research as a Responsibility of Every Scientist}

Customer oriented R\&D means to link customer problems and specific technological competitive advantages. Including business unit managers in steering committees of research projects, or having business units sponsor half of the corporate research budget is not the right approach: This is usually detrimental for long-term innovation. Customer orientation is a mindset permeating the entire company and not stopping short of research. It must be integrated with other corporate responsibilities and explicitly supported by corporate strategy. Every scientist must at least be aware of possible applications of his research. Unfortunately, consequent customer focus in research is restricted by bureaucratic structures and therefore calls for sometimes unconventional forms of project organizations. 
At the level of the individual, customer orientation requires strong interpersonal skills. The customer is often unaware of the technical possibilities, while the scientist is ignorant about market preferences and practical requirements. Together, they must forge a commonly accepted solution, merging implicit and explicit knowledge about technologies and markets. Often, these solutions are radically different from the starting points of either party - but true innovation is based on radical advances in technology and market reach.

Technology development is a team sport; key players include not only the researcher, but also development engineers, product and manufacturing engineers, suppliers, and marketing and sales staff. Involving potential $R \& D$ customers early in the research process is beneficial for customers' acceptance, raises the scientists credibility and his understanding of the customers' needs and problems. Thus, everyone involved will feel ownership and assume responsibility for the project. Contributions from a team that engages a diverse range of stakeholders significantly enriches the quality of research. Individuals familiar with both the scientific and the business world are in a unique position to translate between research and customers. Cross-functional teams not only enrich the diversity of input, they also facilitate the transfer of knowledge and help focus the conceptualization of marketable technology.

\section{A Transfer-Oriented Model for Research Management}

In industrial research, the problem is not the lack of creative ideas but the lack of focus of an abundance of ideas. Research management is about selecting the right ideas and having them prepared and refined for implementation. The goal of industrial research is to provide solutions that can be turned into saleable products by development. Whether these ideas have been created by the firm's own research or whether they have been acquired externally is, in effect, unimportant. The transfer of ideas, knowledge, and technology into successful development projects is the paramount task of research and technology development: Knowledge transfer to development and other downstream corporate functions is the only raison d'être for industrial research.

Research management is about the following three steps: to ensure the right ideas are selected, to execute the right projects, and to transfer their results to development 
(Fig. 10, [47]). This is a gradual transition from what is possible to what is desirable to what is necessary. In each step, customer orientation helps to lead the way.

1. Ensuring the right ideas are selected (filter mechanism): Filtering ideas is a profit-oriented evaluation of project proposals. Technology strategy and market strategy are balanced (see e.g. [29]). Only high-potential ideas may be selected to ensure the quality of development projects in terms of technological maturity and customer perception. Roadmapping, technology synchronization and efficient internal review networks are powerful tools to identify and prioritize blockbuster ideas.

2. Ensuring the right questions are asked (project creation): Asking the right questions fundamentally depends on the continuous and bi-directional information flow between $\mathrm{R}$ and $\mathrm{D}$. Researchers with their insight into technical feasibility must match their work with the developers' ideas about market acceptance in order to design the fundamentals for profitable products. Crossfunctional teams, stakeholder integration and lead users help to bundle ideas into successful projects.

3. Ensuring the results are properly implemented (transfer): Some research results rot in their shelves because development has no use for them (a project creation and filtering problem), or because they are difficult to assess, access, and apply (a transfer problem). Cooperation at a strategic and project level facilitates the alignment between research and development activities. Joint projects, internal job rotation and team ownership of technology to be transferred ensure smoother adoption of research results in customer operations.

// Fig. 10 about here //

Insufficient technology transfer is one of the key weaknesses in industrial R\&D-it is also the sign of insufficient customer-orientation. Research should take an active stance in facilitating and supporting technology transfer between research and development. A research department that considers itself a free-service institution is unlikely to promote technology transfer to development and runs the risk of failing to meet important customer needs (ivory tower syndrome). The right and efficient transfer is therefore fundamentally based on finding the right ideas and selecting the right projects. 


\section{Conclusion}

'Seamless innovation processes' are requested by several authors and practitioners (e.g. [44], [50]). But 'seamless' means no walls whatsoever between research and development: This is often harmful for the long-term innovativeness and stability of research. Despite the incurred transfer problems, research is thus often separated from development. 'Seamless transfer' then not only involves bridging between two corporate functions, it also involves overcoming geographical distances, ensuring technology synchronization, and dealing with fundamentally different attitudes of professionals in science and engineering. Customer effective research without efficient technology transfer is impossible.

The success of customer oriented research management depends on the selfunderstanding of modern industrial research centers as goal-oriented solution providers. But fulfilling short-term requirements of customers means not to neglect the long-term innovation capabilities. These challenges include the surrender of ownership to customers, the simultaneous pursuit of research, development, and manufacturing targets, the appropriate balance of technology-push and market-pull, and the team-based cross-disciplinary approach to customer-interaction. Customer orientation is a responsibility of every research and every engineer, regardless of their primary assignments. Customer orientation must be supported at all major levels of corporate activity, including strategy development, project execution, and informal networking. As seamless innovation remains a rather idealistic concept, customer oriented research must focus on developing the transferring skills of its scientists. In such a transfer model we identified three important tasks: selecting the right ideas, creating the right projects, and ensuring the right transfer. After all, the transfer of useful knowledge to development and other customers is the only raison d'être for industrial research.

\section{Acknowledgments}

The authors would like to thank Prof. Claus Weyrich of Siemens, Dr. Martin Schadt of Rolic, and Dr. Holger Haedrich of the University of St. Gallen for their contribution in the original case studies presented in this article. We are also indebted to Dr. C. Carl 
Pegels and a number of anonymous referees for their insightful comments on earlier drafts of this paper. One of the authors, Maximilian von Zedtwitz, gratefully acknowledges the support of the Swiss Science Foundation, grant no. 81SG-54854. 


\section{References}

[1] Gassmann, O.; von Zedtwitz, M. (1996): Marktorientiertes Forschungsmanagement, in: Wissenschaftsmanagement 3/1996, 138-144.

[2] Boutellier, R.; Gassmann, O.; von Zedtwitz, M. (1999): Managing Global Innovation. Springer: Berlin, New York, Tokyo.

[3] Gassmann, O. (1997): Internationales F\&E-Management, Oldenbourg: Munich, Vienna.

[4] Edelheit, L. (1998): GE's R\&D Strategy: Be Vital, in: Research Technology Management 41, 2, 21-27.

[5] Whitley, R.; Bean, A.; Russo, M. (1998): Using the IRI/CIMS R\&D Database, in: Research Technology Management 41, 2, 12-13.

[6] Groenveld, P. (1997): Roadmapping Integrates Business and Technology, in: Research Technology Management 40, 5, 48-55.

[7] Weyrich, C. (1996): Zentrale Forschung und Entwicklung als Speerspitze der internationalen Innovationsaktivitäten bei Siemens, in: Gassmann, O.; von Zedtwitz, M. (Eds.), Internationales Innovationsmanagement, Vahlen: Munich. 119-125.

[8] Weyrich, C. (1995): Corporate Research (1995): Spearheading Innovation, in: Siemens Review, R\&D Special (Fall), 1-3.

[9] Herbert, E. (1990): How Japanese Companies Set R\&D Directions, in: Research Technology Management 33, 5, 28-37.

[10] Imwinkelried, B. (1996): Internationales Innovationsmanagement bei ABB am Beispiel der neuen Gasturbinenfamilie GT24/GT26, in: Gassmann, O.; von Zedtwitz, M. (Eds.), Internationales Innovationsmanagement, Vahlen: Munich. 83-104.

[11] Allen, T.J. (1977): Managing the Flow of Technology, Cambridge.

[12] Patel, P.; Pavitt, K. (1992): Large Firms in the Production of the World's Technology: an Important Case of Non-Globalisation, in: Granstrand, Ove / Håkanson, Lars / Sjölander, Sören (Eds.): Technology Management and International Business: Internationalization of R\&D and Technology, Wiley: Chichester. 53-73.

[13] Haedrich, H. (1996): Marktorientiertes Forschungsmanagement, in: Gassmann, O.; von Zedtwitz, M. (Eds.), Internationales Innovationsmanagement, Vahlen: Munich. 127-142.

[14] Roberts, E.B.; Malone, D.E. (1996): Policies and structures for spinning off new companies from research and development organizations, in: Research Policy $26,1,17-48$.

[15] von Zedtwitz, M.; Schadt, M.; Brauchli, M. (1996): Überwindung nationaler Grenzen am Beispiel der Liquid Crystal Display (LCD)-Technologie, in: Gassmann, O.; von Zedtwitz, M. (Eds.), Internationales Innovationsmanagement, Vahlen: Munich. 143-154.

[16] Frosch, R.A. (1996): The Customer for R\&D is Always Wrong, in: Research Technology Management 39, 6, 22-27. 
[17] Detz, C.M. (1996): Corporate-Supported Research in a Reengineered Technology Organization, in: Research Technology Management 39, 4, 30-32.

[18] Cohen, H.; Keller, S.; Streeter, D. (1979): The Transfer of Technology from Research to Development, in: Research Technology Management 22, 3, 11-17.

[19] Gomory, R. (1989): Moving IBM's Technology From Research to Development, in: Research Technology Management 32, 6, 27-32.

[20] Nitta, T.; Belady, L.A. (1997): A Productive Technology Transfer Program for Research Laboratories in Large Industrial Companies, in: Hirasawa, R.: Challenges for the 21st Century. Proceedings of the 7th International Forum on Technology Management, Kyoto, Nov 3-7. 260-265.

[21] Eidt, C.; Cohen, R. (1997): 'Reinventing' Industrial Basic Research, in: Research Technology Management 40, 1, 29-36.

[22] Cohen, L.; Kamiensji, P.; Espino, R. (1998): Gate System Focuses Industrial Basic Research, in: Research Technology Management, 4, 41, 34-37.

[23] Chester, A.N. (1995): Measurements and Incentives for Central Research, in: Research Technology Management, 38, 4, 14-22.

[24] Khurana, A.; Rosenthal, S.R. (1997): Integrating the Fuzzy Front End of New Product Development, in: Sloan Management Review (Winter), 103-120.

[25] Eldred, E.; McGrath, M. (1997): Commercializing New Technology - I, in: Research Technology Management 40, 1, 41-47.

[26] Eldred, E.; McGrath, M. (1997): Commercializing New Technology - II, in: Research Technology Management 40, 2, 29-33.

[27] Iansiti, M. (1998): Technology integration: making critical choices in a dynamic world. Boston: Harvard Business Press.

[28] Yin, R.K. (1988): Case Study Research: Design and Methods, Newbury Park, London, New Delphi.

[29] Wheelwright, S.C.; Clark, K.B. (1992): Revolutionizing Product Development Quantum Leaps in Speed, Efficiency, and Quality. New York: The Free Press.

[30] Daimler-Benz (1998): Erfolgsmassstab Transfer, in: Daimler-Benz Headline, Nr. 5. Stuttgart: Daimler-Benz, 6-7.

[31] Leonard-Barton, D. (1995): Wellsprings of Knowledge - Building and Sustaining the Sources of Innovation. Boston: Harvard Business School Press.

[32] Pavitt, K. (1985): Technology Transfer among the Industrially Advanced Countries: An Overview, in: Rosenberg, N.; Frischtak, C. (1985, Eds.): International technology transfer. New York: Praeger, 3-23.

[33] Goto, T. (1997): Technology Transfer as a Cornerstone of Globalization and Innovation, in: Hirasawa, R.: Challenges for the 21 st Century. Proceedings of the 7th International Forum on Technology Management, Kyoto, Nov 3-7. 475-480.

[34] Wang, W. (1997): Technology Transfer to and Absorption in a Developing World - Case Studies of Ericsson in Malaysia and China, in: Mekanisten, No. 4, 3648.

[35] Sartain, J.R.; Dean, B.V. (1998): International Technology Transfer Sucess Factors in Hewlett-Packard, in: Lefebvre, L.A.; Mason, R.M.; Khalil, T. 
(1998, Eds.): Management of Technology, Sustainable Development and EcoEfficiency, Amsterdam: Elsevier, 309-318.

[36] Souder, W.E.; Padmanabhan, V. (1989): Transferring New Technologies from R\&D to Manufacturing, in: Research Technology Management 32, 5, 38-43.

[37] Brockhoff, K.K.; Chakrabarti, A.K.; Hauschildt, J.; Pearson, A.W. (1996): Managing Interfaces, in: Gaynor, G. H. (Ed.): Handbook of Technology Management, New York, 27.1-27.17.

[38] Doheny-Farina, S. (1992): Rhetoric, innovation, technology: case studies of technical communication in technology transfers. Cambridge: The MIT Press, $1-30$.

[39] Nonaka, I.; Takeuchi, H. (1995): The Knowledge-Creating Company. How Japanese Companies Create the Dynamics of Innovation, New York: Oxford.

[40] Leifer, R.; Triscari, T. (1987): Research versus Development: Differences and Similarities, in: IEEE Transactions on Engineering Management, Vol. EM-34, No. 2, 71-78.

[41] Odlyzko, A. (1996): We Still Need Unfettered Research, in: Research Technology Management 39, 1, 9-11.

[42] Brockhoff, K. (1997): Industrial Research for Future Competitiveness, Berlin, Heidelberg, New York: Springer.

[43] Boutellier, R.; Gassmann, O.; von Zedtwitz, M. (1997): Innovation and Phases in Transnational R\&D, in: Hirasawa, R. (Ed.): Challenges for the 21th Century Networking East and West, 7th International Forum on Technology Management, 3-7 November, Kyoto, Japan, 481-488.

[44] Dimanescu, D.; Dwenger, K. (1996): World-Class New Product Development. New York: Amacom.

[45] Gassmann, O.; von Zedtwitz, M. (1997): Organization of Industrial R\&D on a Global Scale, in: Pearson, A.; Butler, J.; Watts, T. (1997, Eds.): Managing R\&D into the 21st Century. Proceedings of the R\&D Management Conference, Manchester, July 14-16.

[46] Gassmann, O.; von Zedtwitz, M. (1998): Organization of Industrial R\&D on a Global Scale, in: R\&D Management, Vol. 28, No. 3, 147-161.

[47] von Zedtwitz, M. (1999): Managing Interfaces in International R\&D. Doctoral Thesis Nr. 2315 University of St. Gallen. Bamberg: Difo-Druck.

[48] Gassmann, O.; von Zedtwitz, M. (1999): New Concepts and Trends in International R\&D Organization: in Research Policy, Vol. 28, 231-250.

[49] Lamnek, S. (1993): Qualitative Sozialforschung, Bd. 2: Methoden und Techniken, Weinheim.

[50] Arthur D. Little (1997): Priority Issues in Technology and Innovation Management: An Arthur D. Little Survey of Management Agendas. 


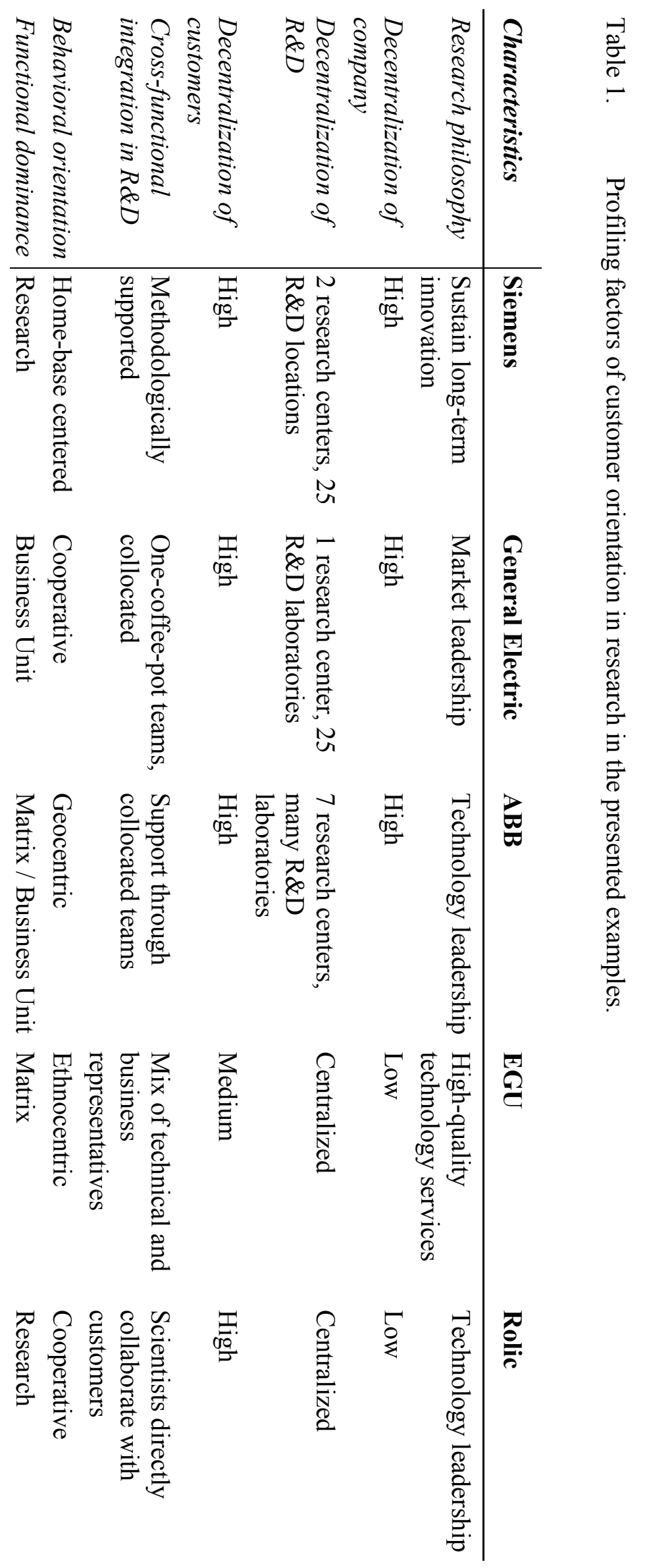




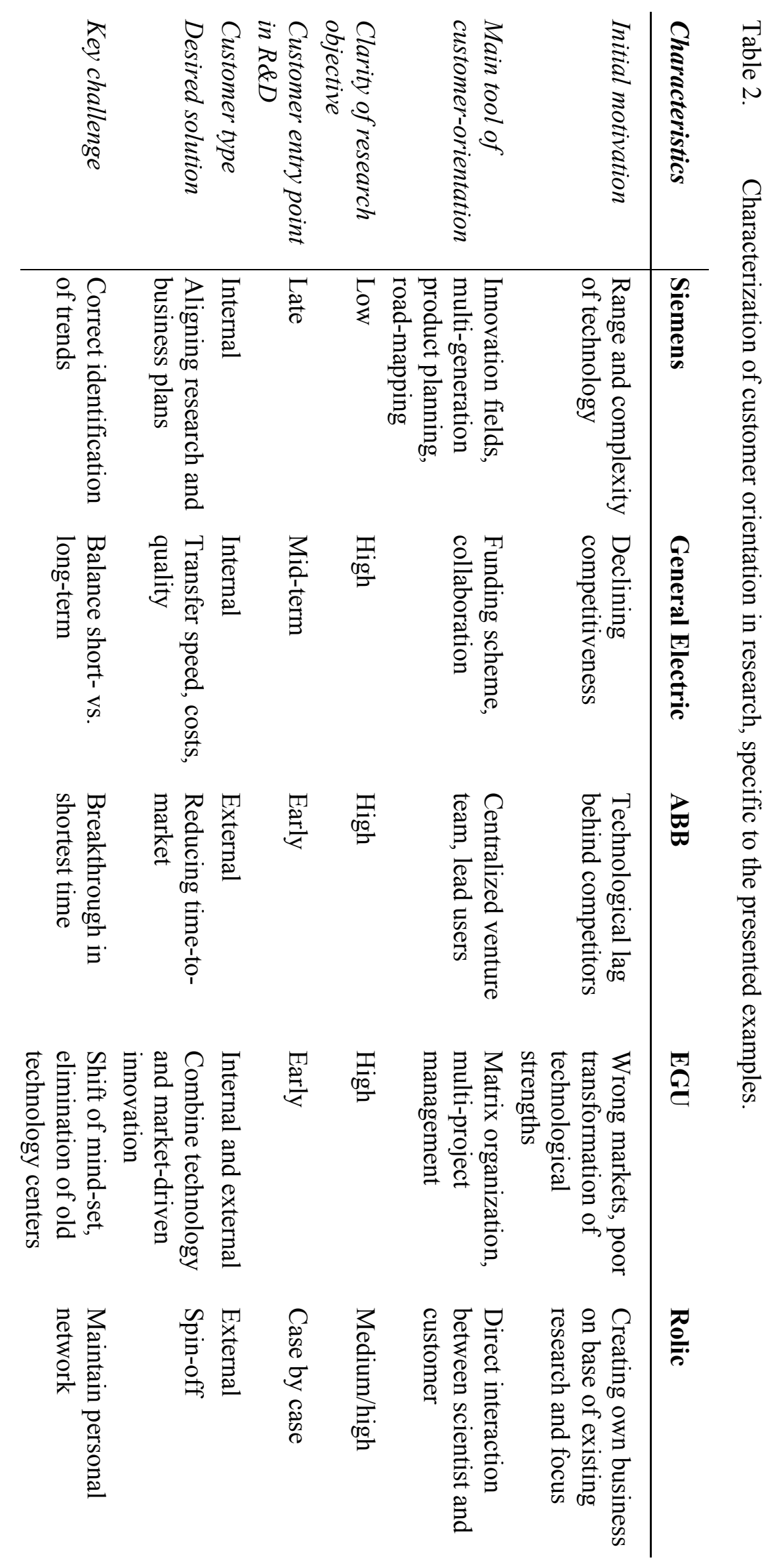


Fig. 1. Corporate research today is funded by a multitude of sources (adapted from [23], see also [2], [3: 70], [4: 21], [5: 12-13]).

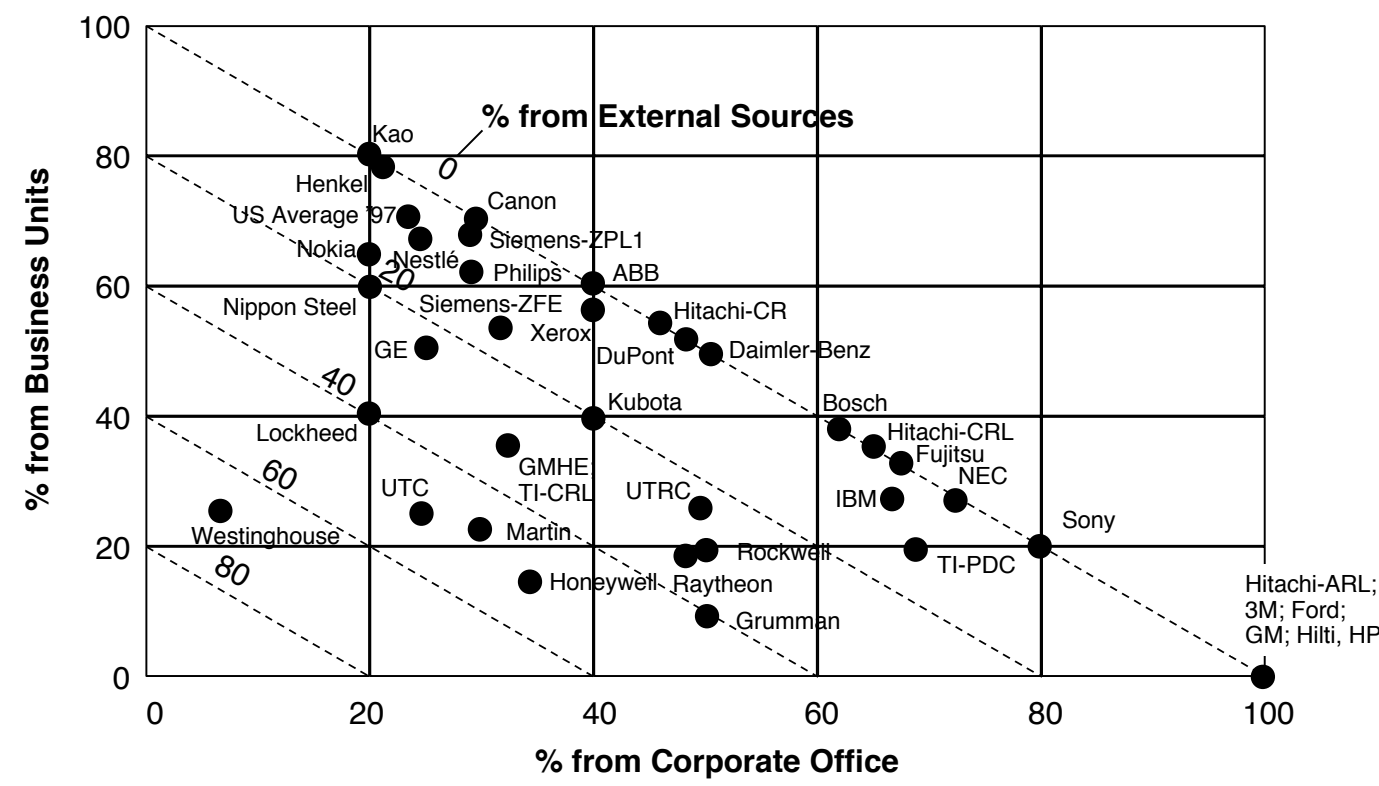

Fig. 2. The research program on international R\&D processes, which included customer orientation in research, was based on 290 interviews in 62 companies.

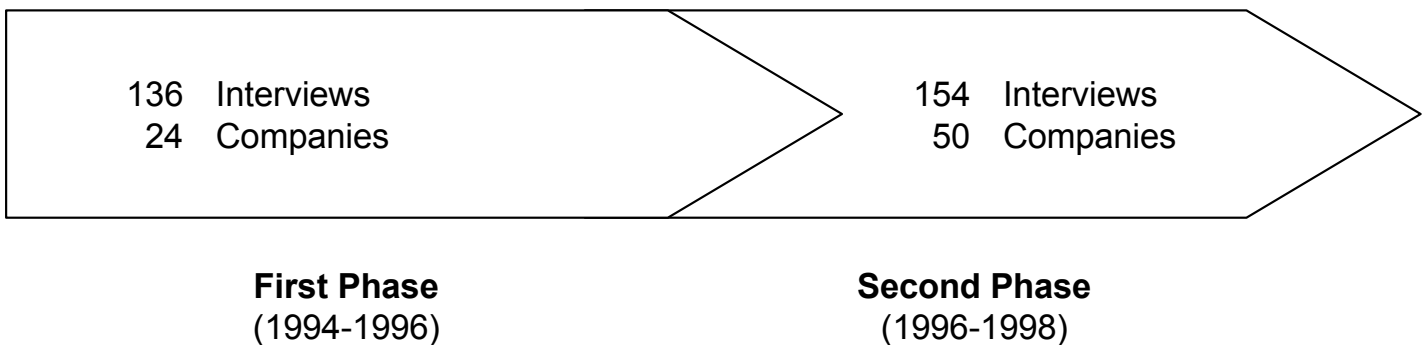

Sum of Interviews: 290

- Document analysis: Project manuals, internal Sum of Companies: 62 documents, presentations, annual reports, publications

- Personal observation: Site visits, work shops, participation in joint projects 
Fig. 3. Organization of Central Research and Development at Siemens [7].

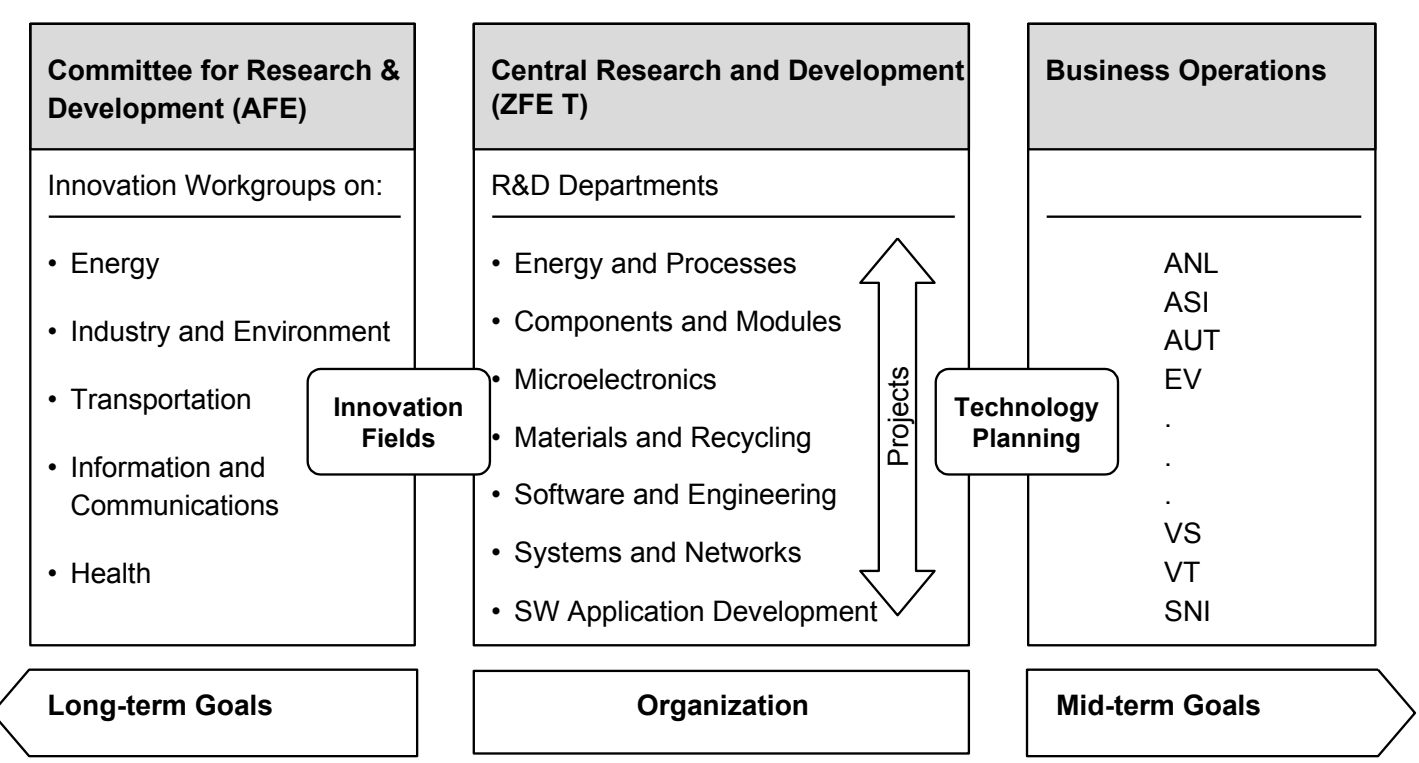


Fig. 4. Technology requirements are fine-tuned through Multiple Generation Product Planning and Core Technology Roadmaps [7].

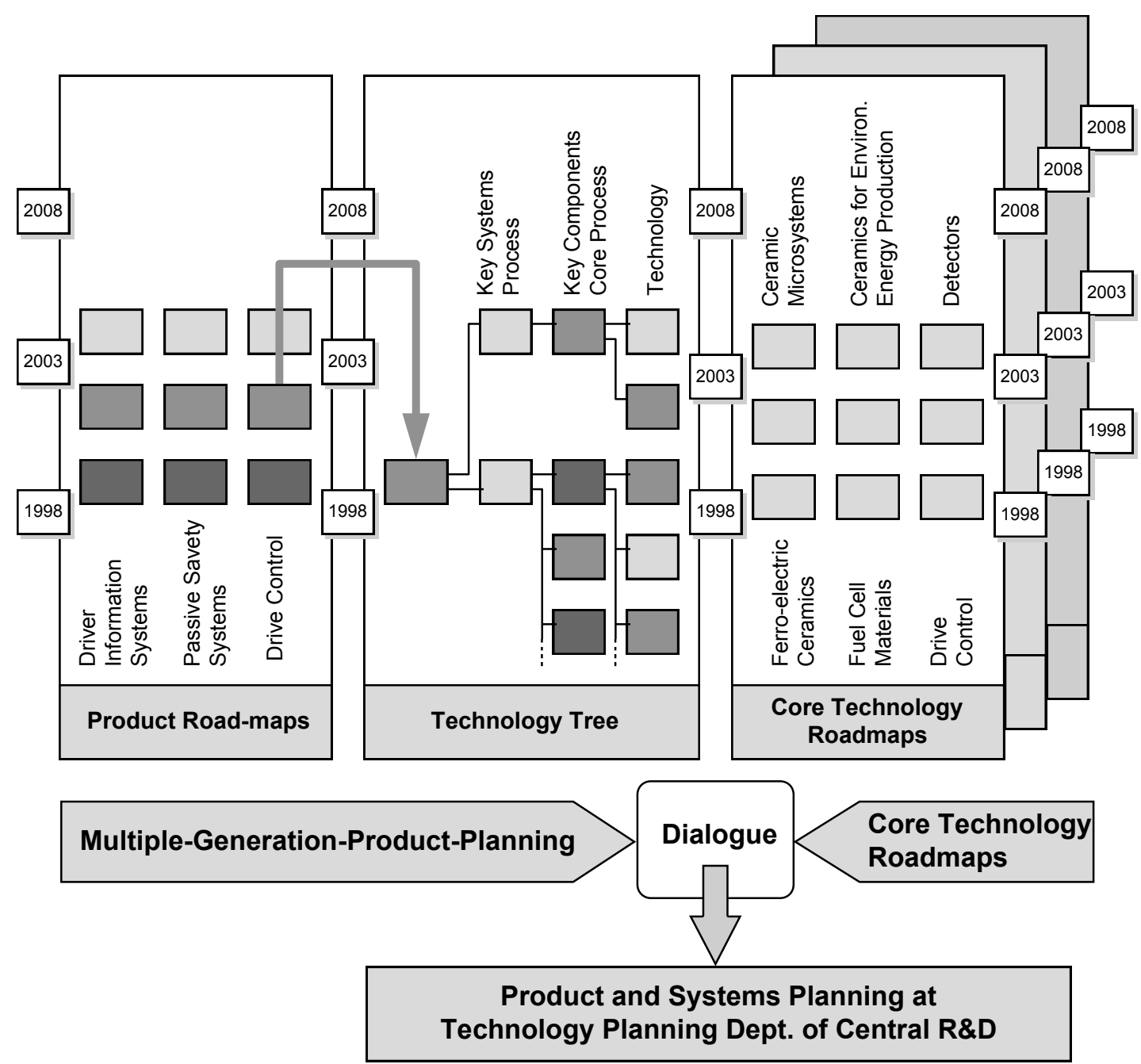


Fig. 5. GE's Corporate R\&D Center serves all GE business units and external customers [4].

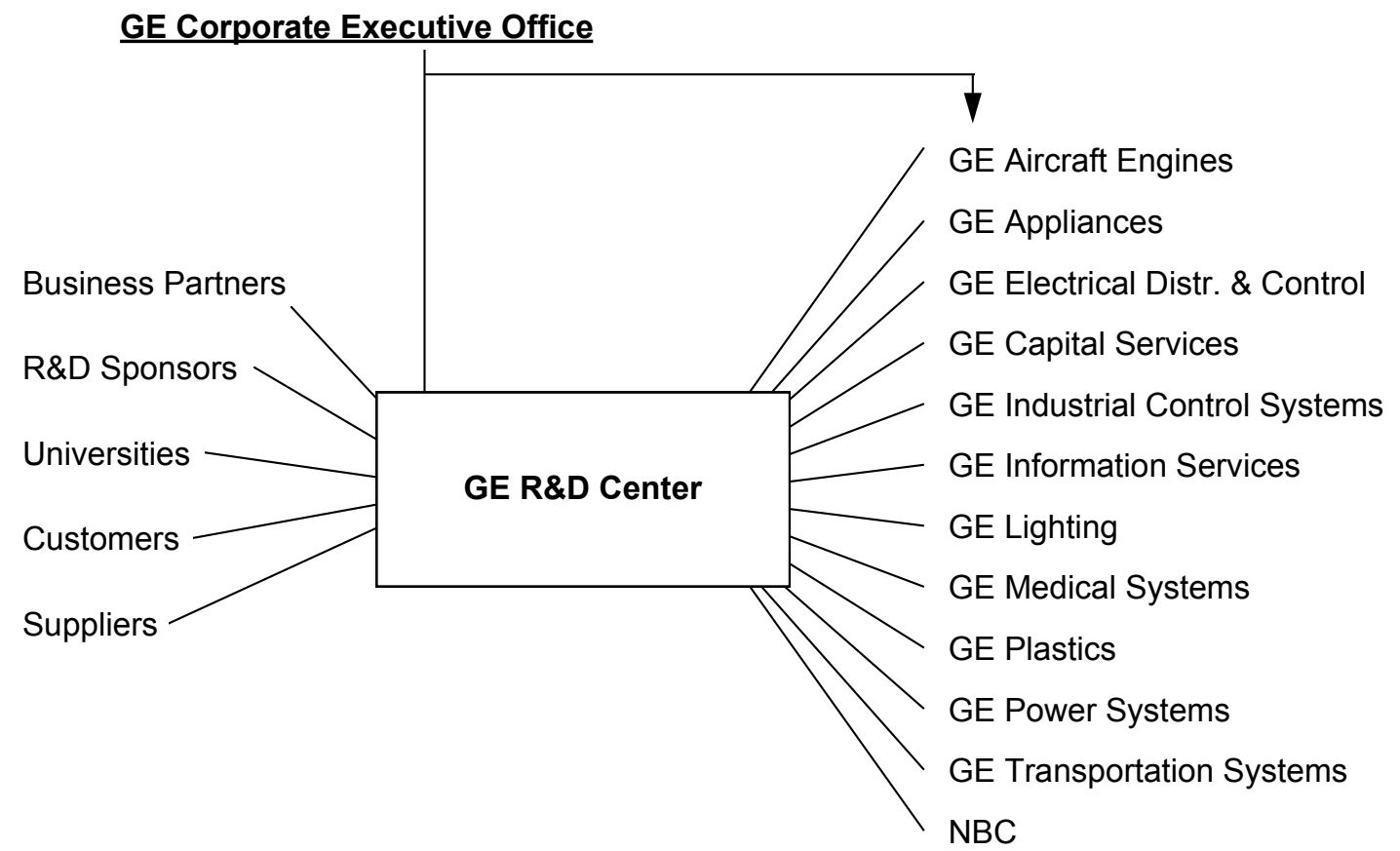

Fig. 6. Centralized venture team for ABB's R\&D on GT24/26 [3].

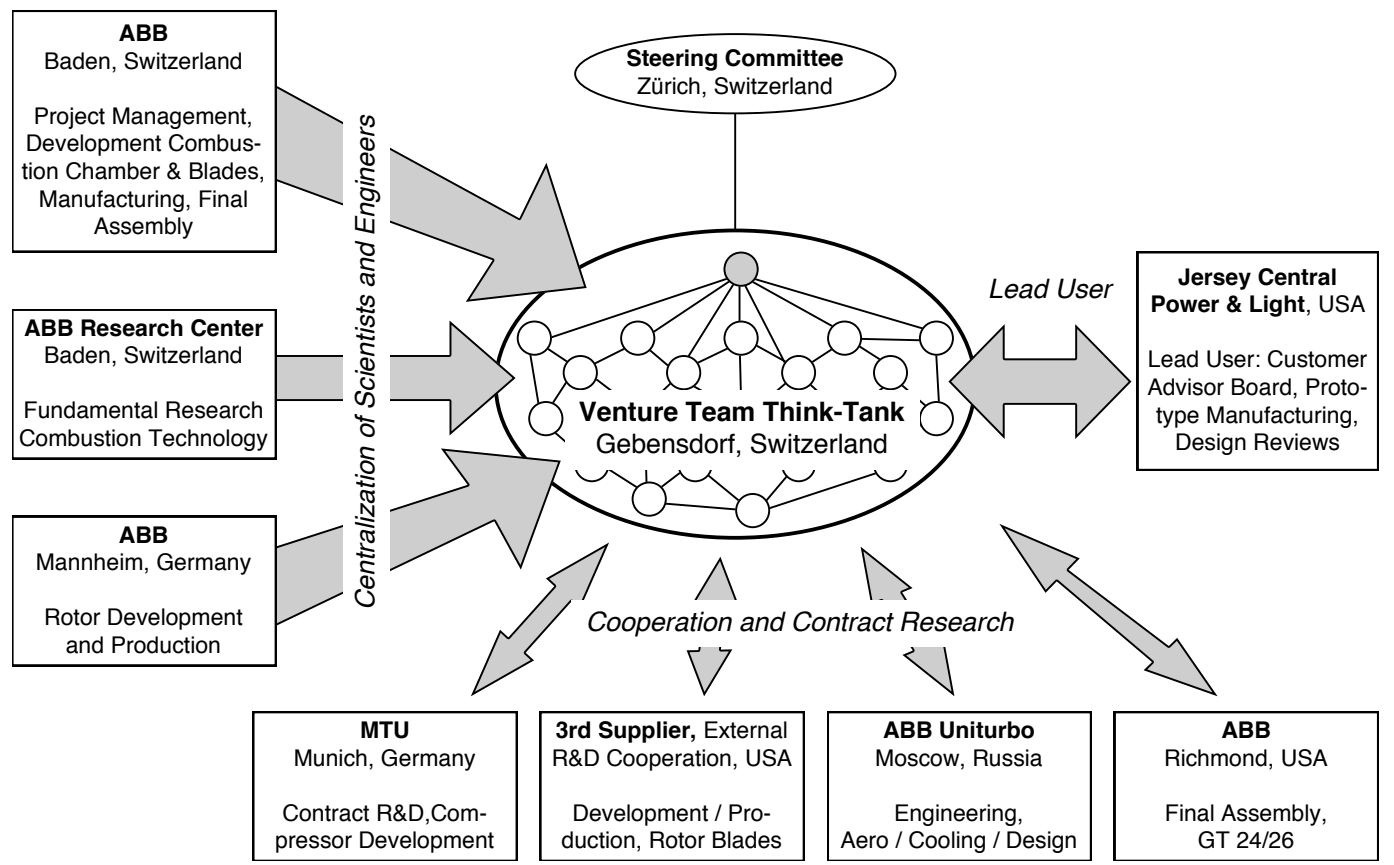


Fig. 7. EGU's organization before the reorganization [13].

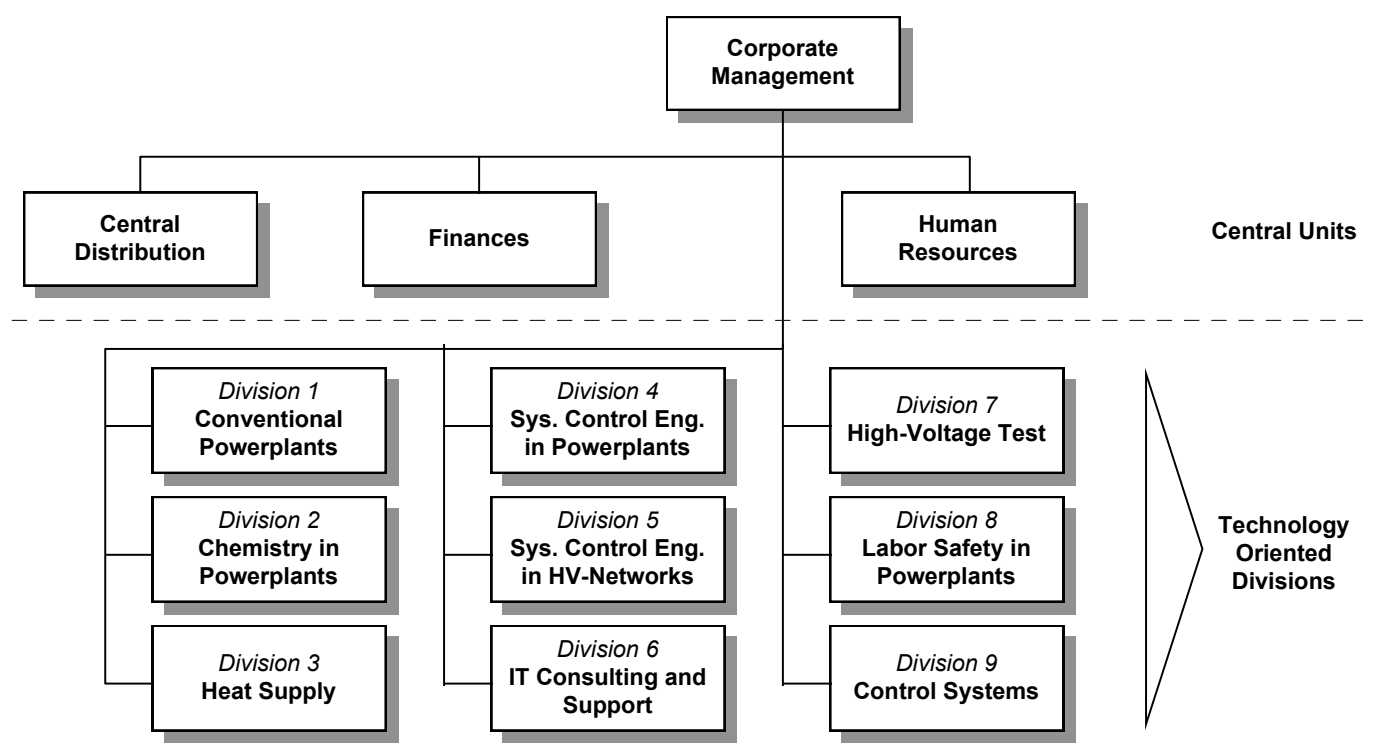

Fig. 8. Matrix organization integrates research and services [13].

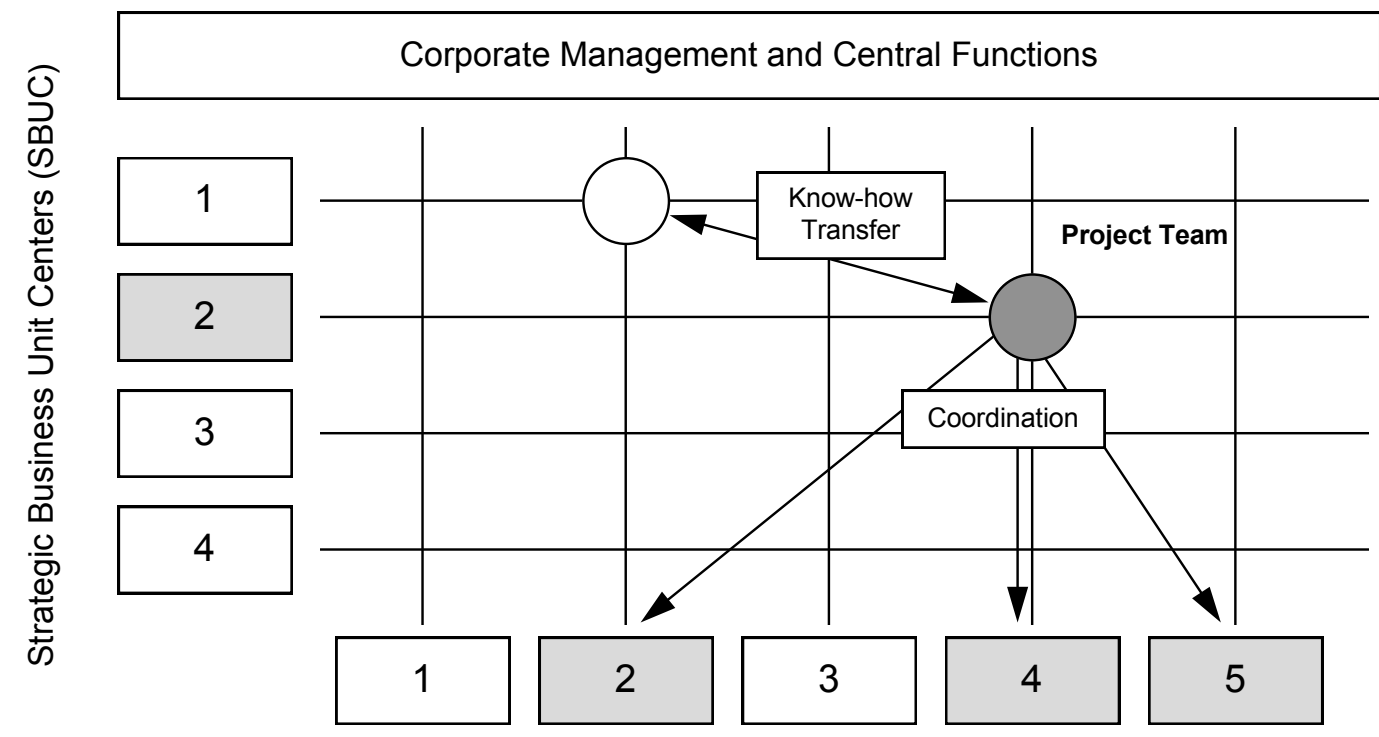

Technology Centers (TC) 
Fig. 9. The path leading to the spin-off of the liquid crystal activities from Roche ([15], [48]).

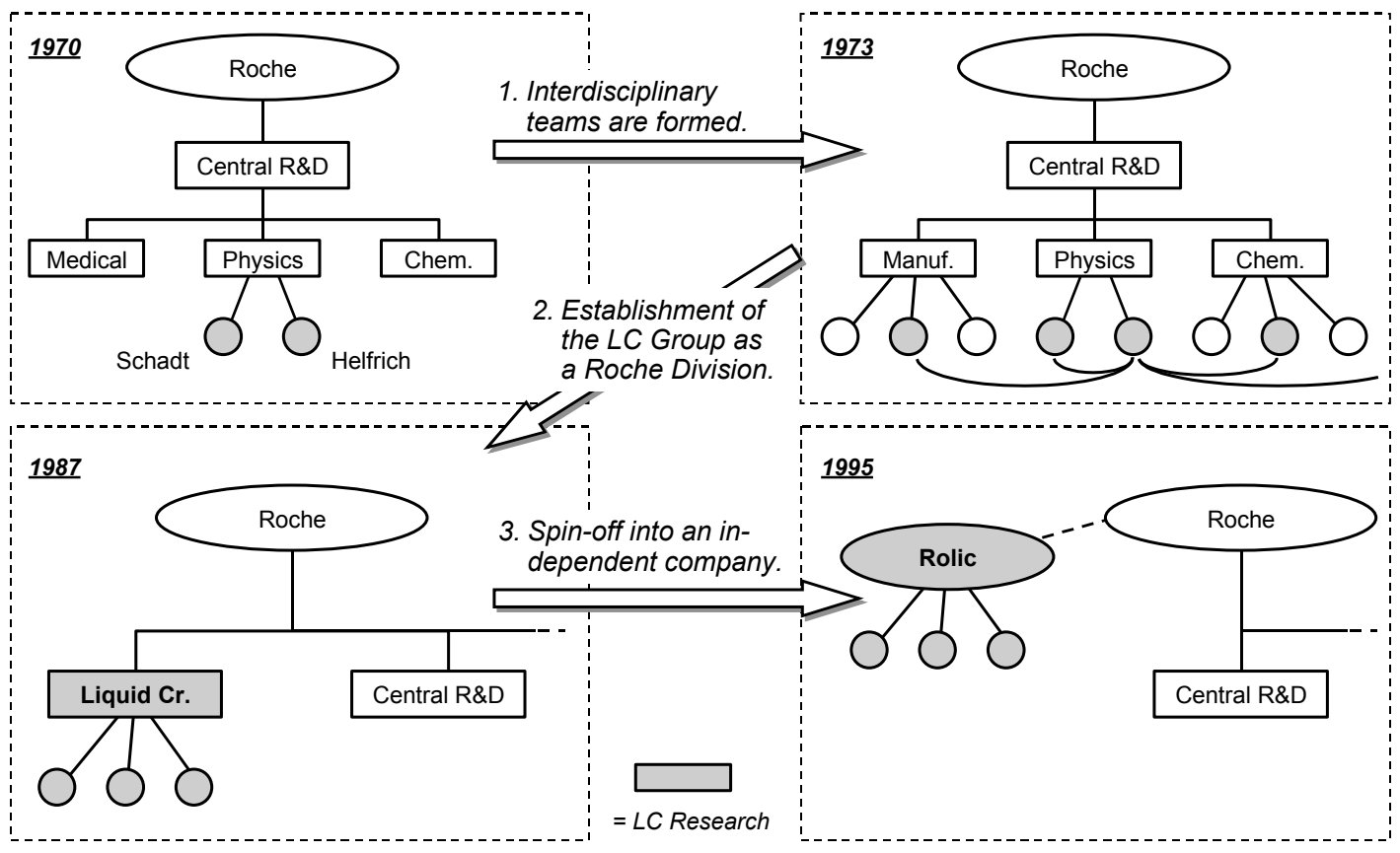


Fig. 10. Research management, comprising the three important tasks for customer oriented knowledge and technology transfer, must make sure that the right ideas are selected, the right projects are created, and the research results are correctly transferred.

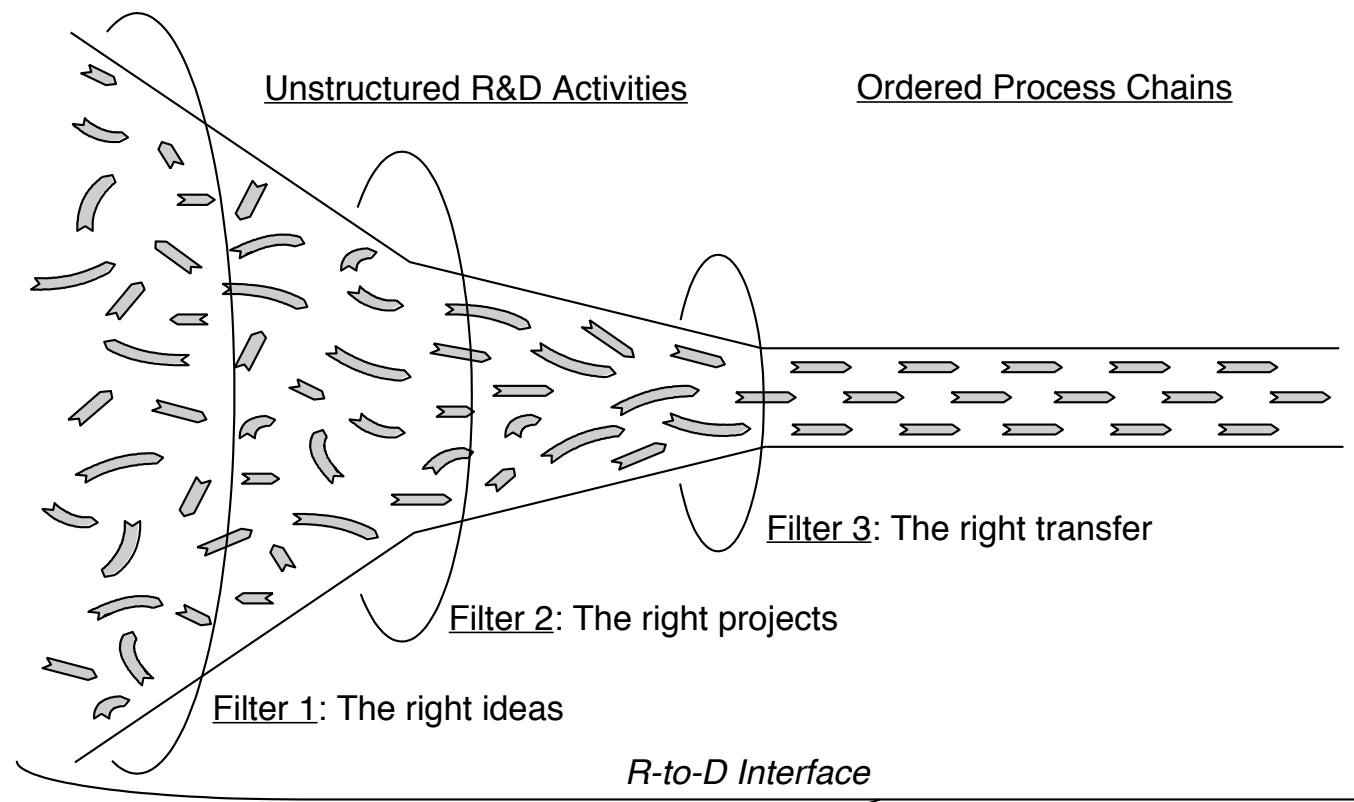

Research 